\title{
A LEXICOGRAPHIC OPTIMIZATION APPROACH FOR BERTH SCHEDULE RECOVERY PROBLEM IN CONTAINER TERMINALS
}

\author{
Qian Zhang, Qingcheng Zeng, Hualong Yang \\ School of Transport Management, Dalian Maritime University, China
}

Submitted 1 December 2013; resubmitted 18 February 2014, 10 May 2014; accepted 25 July 2014

\begin{abstract}
In container terminals, the planned berth schedules often have to be revised because of disruptions caused by severe weather, equipment failures, technical problems and other unforeseen events. In this paper, the problem of berth schedule recovery is addressed to reduce the influences caused by disruptions. A multi-objective, multi-stage model is developed considering the characteristics of different customers and the trade-off of all parties involved. An approach based on the lexicographic optimization is designed to solve the model. Numerical experiments are provided to illustrate the validity of the proposed Model A and algorithms. Results indicate that the designed Model A and algorithm can tackle the berth plan recovery problem efficiently because the beneficial trade-off among all parties involved are considered. In addition, it is more flexible and feasible with the aspect of practical applications considering that the objective order can be adjusted by decision makers.
\end{abstract}

Keywords: container terminals; berth schedule; disruption management; lexicographic optimization.

\section{Introduction}

Berths are important resource of container terminals and good scheduling of berths can improve operation efficiency, decrease the vessel turnaround time and lead to higher competitive of container terminals. However, during operation, irregular disruptions caused by unforeseen events such as severe weather, equipment failures and technical problems etc. often occur. These events may cause tremendous disruption, and thus decrease the operation efficiency and service level of container terminals. Once these disruptions happen, the initial plan may be infeasible, and modification of current or future schedule should be undertaken to minimize the negative impacts of the disruption.

Disruption management is a methodology that copes with disruptions in real time (Yu, Qi 2004). The main difference between disruption management and rescheduling is that rescheduling focuses on minimizing of the original objective function while disruption management aims to minimize the deviation of the new schedule from the original one (Kuster et al. 2008). Disruption management is a research field received an increasing attention, and the successful applications include airline management, supply chain and machine scheduling etc.
Comparing existed studies on disruption management, the disruption management of berth schedule has following characteristics:

- Complex constraints. The operation in container terminals consists of many interrelated sub-processes. When optimizing the recovery scheme of berth schedule, the relation of berth schedule with quay crane schedule and other sub-processes should be considered.

- Benefit trade-off and customer priorities. The modification of berth schedule influences the benefits of ship-owners, terminal operators, port authorities and trailer companies etc. Moreover, the sensitivity to ship delay differs according to different customers. Beneficial trade-off and customer characteristics should be considered when modelling the problem of berth schedule recovery.

- Computation complexity. Berth schedule is an NP-hard problem (Kim, Moon 2003), and the characteristics of disruption management require the high speed and efficiency of solution algorithms.

This paper addresses the problem of berth schedule recovery based on disruption management methodology. A multi-objective, multi-stage model is developed

Corresponding author: Qingcheng Zeng

E-mail: zqcheng2000@hotmail.com 
considering the characteristics of different customers and the benefit trade-off of all parties involved in the container terminal system. The paper is organized as follows. In Section 1, a literature review on berth schedule is provided. In Section 2, a model for berth schedule recovery is developed. Lexicographic optimization approach is presented in Section 3. Solution algorithms are designed in Section 4. Numerical experiments are provided to illustrate the validity of the proposed method in Section 5. Conclusions are given in last section.

\section{Literature Review}

Issues related to berth schedule have been receiving much attention recently. Many models and algorithms have been developed to optimize the berth allocation plan. Nishimura et al. (2001) developed a discrete berth schedule model and designed a solution method based on genetic algorithm. Imai et al. (2003) further developed a berth schedule model considering the docking priorities of different shipping companies. Kim and Moon (2003) solved the discrete berth schedule model with Simulated Annealing (SA). Imai et al. $(2005,2007)$ developed models for continuous berth schedule problem and designed heuristics algorithms to solve the models. Wang and Lim (2007) treated the berth allocation problem as a multi-stage decision problem and solved the problem with a stochastic beam-searching algorithm.

There is an inherent interrelationship between the allocation and scheduling of berth and quay cranes. Increasing studies are focused on simultaneous berth and quay crane scheduling. Park and Kim (2003) developed a mixed integer program to determine the berthing positions, berthing times, and the quay crane assignments. Imai et al. (2008) developed a model to optimize berth schedule and quay crane allocation simultaneously, and a heuristic algorithm was designed to solve the problem. Meisel and Bierwirth (2009) also studied the simultaneous berth allocation and quay crane assignment problem. A local refinement procedure and two meta-heuristics are presented. Moreover, in the model of simultaneous berth and quay crane scheduling problem developed by Liang et al. (2009), the influence of quay crane quantity on average operation efficiency was considered.

The above studies were based on the supposition of certain environment, and no impact of uncertainty factors on berth schedule was considered in these studies. However, uncertainty (e.g. vessel arrival and loading/unloading time) and disruption events widely exist in terminal operation system and influence the performance of terminal operation. Researchers begin to address the issues of terminal scheduling with uncertainty. Han et al. (2010) studied the berth and quay crane scheduling problems with uncertainties of vessel arrival time and container handling time. A mixed integer-programming model was proposed to generate robust berth and quay crane schedule. Angeloudis and Bell (2010) studied job assignments under uncertainty for Automated Guided Vehicle (AGV) in automated container terminals. A new AGV dispatching approach was developed, which can operate under uncertain conditions within a detailed container terminal model.

Disruption management is another method to tackle scheduling problem with uncertainties. Models and algorithms have been developed to tackle disruptions in supply chain, machine scheduling and airline operation etc. Yu and Qi (2004) developed a disruption management model for airline scheduling and designed a solution system called Crew-Solver. Liu et al. (2008), Abdelghany et al. (2008), and Clausen et al. (2010) further analysed the main problems in airline disruption management and developed disruption recovery models. Oke and Gopalakrishnan (2009), Xiao et al. (2007) studied the coordination and recovery of supply chain after disruptions. Petrovic and Duenas (2006), Qi et al. (2006) developed disruption recovery models for machine scheduling and designed solution algorithms. Walker et al. (2005) developed a disruption management model for recovery of rail timetable schedule and crew assignment.

Based on the existed studies, this paper proposed a multi-objective and multi-stage disruption recovery model for berth schedule. The model considers the sensitivity of different customers to vessel delay and the benefit trade-off of different parties. The contributions of this paper are:

- Despite the increasing importance of uncertainty and disruptions in container terminals, limited research is focused on the berth reschedule method. This paper fills the gap by developing Model $A$ and algorithms for berth schedule recovery model.

- A multi-stage and multi-objective model is proposed to minimize the negative impacts of disruptions on berth schedule. This model considers the characteristics of different customers and benefit trade-off of all parties involved, thus can improve the scientific of berth schedule recovery.

- A method based on lexicographic optimization is designed to solve the model. Lexicographic optimization establishes a hierarchical order among all the optimization objectives. Comparing to Pareto optimality method, it is more flexible and feasible with the aspect of practical applications as the objective order can be adjusted by decision makers.

\section{Model for Berth Schedule Recovery}

\subsection{Model Assumptions}

Berth schedule is used to determine the berth time and position of each vessel within a given planning horizon considering priority, length, arrival and handling time of each vessel. In this paper, the continuous berth schedule method is used, and the quay crane assignment is considered. The berthing position, time and number of quay craned assigned to each vessel are optimized. The objective of berth schedule is to minimize the penalty cost resulting from vessel delays and the additional cost resulting from no-optimal berthing location of vessels. 
We formulate the model for berth schedule recovery considering that the berth schedule is pre-determined. Berth schedule is represented by a two-dimension axis, with horizontal axis representing the berth position and vertical axis representing the berth time, and the following assumptions are made:

- there are no physical restrictions, i.e., the water depth of terminal berth can meet all vessels;

- vessel operation time is inverse proportion to the number of quay cranes assigned;

- there is a minimum number of quay cranes assigned to a vessel;

- vessel operation lasts from its berthing time to departure time.

In modelling berth schedule recovery problem, the theory of disruption management is used. Disruption management is a methodology to tackle disruptions in real time (Yu, Qi 2004). The main difference between disruption management and rescheduling is that rescheduling focuses on finding a schedule which is optimal in terms of the original objective function whereas disruption management aims to minimize the deviation of the new schedule from original one (Qi et al. 2006). Thus, the disruption management problem for berth schedule recovery in this paper considers two types of objectives. The first type relates the original objective function, such as minimization of operation cost and vessel delay cost, and the second type is to minimize the deviation from the original schedule.

\subsection{Variables and Parameters}

To formulate the disruption recovery model, the following parameters and variables are defined:

\section{Parameters:}

$L$ - total length of a berth line which is denoted by the number of $10 \mathrm{~m}$ segments;

the number of unfinished vessels when disruptions happen;

$Q$ - the number of quay cranes;

$T$ - set of time points represented by hour;

$a_{i}$ - expected arrival time of vessel $i$;

$d_{i}$ - expected departure time of vessel $i$, which is usually determined by the contracts between shipping companies and terminal operators;

$l_{i}$ - the length of vessel $i$, which is represented by the number of $10 \mathrm{~m}$ segments;

$b_{i}$ - the optimal berthing location of vessel $i$, where yard trailers have the minimum transport cost;

$Q_{i}^{\min }$ - the minimum number of quay cranes required to serve vessel $i$ simultaneously;

$Q_{i}^{\max }$ - the maximum number of quay cranes allowed to serve vessel $i$ simultaneously;

$w_{i}$ - the number of quay crane hours needed to finish the operation of vessel $i$;

$c_{1 i}$ - the unit additional cost (yard trailers transport cost) of vessel $i$, resulting from non-optimal berthing location, which is given as USD/m;

$c_{2 i}$ - the unit delay penalty cost of vessel $i$, which is given as $\mathrm{USD} / \mathrm{h}$;

$c_{3}$ - unit operation cost rate of quay cranes, which is given as USD/h;
$M$ - a sufficient large constant;

$x_{i}^{0}$ - the berthing position of vessel $i$ in initial berth schedule;

$y_{i}^{0}$ - the berthing time (operation starting) of vessel $i$ in initial berth schedule.

Variables:

$x_{i}$ - integer, the berthing position of vessel $i$ in recovery schedule;

$y_{i}$ - integer, the berthing time of vessel $i$ in recovery schedule;

$e_{i}$ - integer, the time that the operation of vessel $i$ is completed according to recovery schedule;

$q_{i t}$ - number of quay cranes assigned to vessel $i$ at time point $t$;

$Z_{i j}^{x}$ - binary, set to 1 if vessel $i$ is located to the left of vessel $j$ in the recovery schedule, and 0 otherwise;

$Z_{i j}^{y}$ - binary, set to 1 if vessel $i$ is berthed before vessel $j$ in the recovery schedule, and 0 otherwise.

\subsection{Model Formulation}

When disruptions happen, recovery scheme is searched based on current resources, constraints and operation states. The berth schedule recovery influences the benefit of terminal operators and liner companies. To reflect the benefit trade-off and decrease disruptions to all parties involved, a multi-objective programming method is used. The objective is to minimize the deviation between initial and recovery schedules, vessel delay and operation cost etc. Thus, the model can be formulated as follows:

$$
\begin{aligned}
& \min f_{1}=\sum_{i=1}^{N}\left(c_{1 i}\left|x_{i}-b_{i}\right|+c_{3} \sum_{t \in T} q_{i t}\right) ; \\
& \min f_{2}=\sum_{i=1}^{N} c_{2 i}\left(e_{i}-d_{i}\right)^{+} ; \\
& \min f_{3}=\sum_{i=1}^{N}\left(x_{i}-x_{i}^{0}\right)^{+} \\
& \text {s. t. } \sum_{i=1}^{N} q_{i t} \leq Q, \forall t \in T ; \\
& \sum_{t \in T} q_{i t} \geq w_{i}, \forall i=1, \ldots, N ; \\
& \sum_{t \in T} q_{i t}=q_{i y_{i}}+q_{i}\left(y_{i}+1\right)+q_{i\left(y_{i}+2\right)}+\ldots+q_{i e_{i}}, \\
& \forall y_{i} \in T, \forall e_{i} \in T ; \\
& Q_{i}^{\min } \leq q_{i t} \leq Q_{i}^{\max }, \forall i=1, \ldots, N, \forall t \in T ; \\
& x_{i}+l_{i} \leq x_{j}+M\left(1-Z_{i j}^{x}\right), \forall i, j=1, \ldots, N, i \neq j ; \\
& e_{i} \leq y_{j}+M\left(1-Z_{i j}^{y}\right), \forall i, j=1, \ldots, N, i \neq j ; \\
& Z_{i j}^{x}+Z_{j i}^{x}+Z_{i j}^{y}+Z_{j i}^{y}>1, \forall i, j=1, \ldots, N, i \neq j ; \\
& y_{i} \geq a_{i}, \forall i=1, \ldots, N ; \\
& x_{i} \in\left\{0,1, \ldots, L-l_{i}\right\}, \forall i=1, \ldots, N ; \\
& Z_{i j}^{x}, Z_{i j}^{y}=1 \text { or } 0, \forall i, j=1, \ldots, N, i \neq j .
\end{aligned}
$$

Eq. (1) is used to minimize the operation cost including additional costs resulting from non-optimal berth locations of vessels and the operation cost of quay cranes. Eq. (2) is used to minimize the vessel delay. Eq. (3) used is to minimize the deviation between 
recovery and initial schedule, namely to minimize the modifications and thus decrease the disruptions.

Constraints are represented by Eqs (4-13). Eq. (4) denotes the maximum of simultaneously used quay cranes. Eqs (5-6) defines the operation starting and ending time for each vessel. Eq. (7) shows the maximum and minimum quay cranes can be assigned to a vessel. Eq. (8) shows the relation of berthing location between two vessels. For example, if vessel $i$ is berthed to the left of vessel $j, Z_{i j}^{x}=1$. Then, $x_{j} \geq x_{i}+l_{i}$, which means that the berthing position of vessel $j$ should be larger than the position of vessel $i$ plus the length of vessel $i$. Eq. (9) shows the relation of berthing time between two vessels. For example, if vessel $i$ is berthed before vessel $j, Z_{i j}^{y}=1$. Then, $y_{j} \geq e_{i}$, which means that the berthing time of vessel $j$ should be larger than the time that the operation of vessel $i$ is completed. Eq. (10) ensures there are no conflicts between two vessels with respect to berthing time and location. Eq. (11) ensures that each vessel berths after its expected arrival time. Eq. (12) ensures that each vessel berths within the quay line. Eq. (13) is binary constraints.

\section{Lexicographic Optimization Approach}

\subsection{Lexicographic Optimization}

Usually, the concept of Pareto optimality is used for the multi-objective optimization problem. A solution $\vec{z}^{*}$ of the multi-objective optimization problem presented in Eqs (1-13) is said to be Pareto optimal if there is not another $\vec{z} \in Z$ that $f_{i}(\vec{z}) \leq f_{i}\left(\vec{z}^{*}\right)$ for all $i \in N$ and $f_{j}(\vec{z}) \leq f_{j}\left(\vec{z}^{*}\right)$ for at least one index $j$. According to the definition of Pareto optimality, moving from one Pareto solution to another needs trading off. Weighting methodology is a widely used trading off approach, in which priority of the objectives are reflected by the weights. However, the most obvious problem with weighting methodology is the difficulty of choosing the weight as it is based either on vague intuition or error experimentation with different weighting values of users (Miettinen 1998). Moreover, it involves a linear combination of different criteria thus has the limitation that can not find solutions in a non-convex region of the $\mathrm{Pa}$ reto front (Li 1996).

The lexicographic optimization is another approach to solve multi-objective problem. In this method, a hierarchical order among all the optimization objectives is established (Prats et al. 2010). If priority exists, a unique solution would exist on the Pareto hyper-surface (Kerrigan, Maciejowski 2002).

A standard process of lexicographic optimization approach is to solve a sequential order of single objective optimization problems. The objective functions are arranged from the most important $f_{1}$ to the least important $f_{n}$. The most important objective function is minimized first $\left(f_{1}^{*}=\min _{z \in \wp}\left(f_{1}(z)\right)\right)$, subject to the original constraints. If there is only one solution, it is the solution of the whole multi-objective problem. Otherwise, the second most important objective function is minimized.
A new constraint is added to ensure that the most important objective function preserves its optimal value. The process goes on iteratively until all the objectives are considered. In this approach, a solution obtained according to a more important objective serves as an additional constraint of a less important objective, which can be represented by:

$$
\begin{aligned}
& f_{i}^{*}=\min f_{i}(z) \\
& \text { s. t. } f_{j}(z) \leq f_{j}^{*}, j=1, \ldots, i-1, i>1 .
\end{aligned}
$$

Eq. (16) represents constraint relaxation, in which $\delta j$ is tolerance percentage determined by decision-maker. With the increase of $\delta j$, the feasible region dictated by the objective functions expands. Different Pareto optimal points can be generated by varying $\delta j$ to tighten or relax the constraints:

$$
f_{j}(z) \leq\left(1+\delta_{j}\right) f_{j}^{*}, j=1, \ldots, i-1, i>1 .
$$

Lexicographic optimization has several advantages over weighting methodology (Marler, Arora 2004), and has been started to be widely used in engineering applications (Ocampo-Martinez et al. 2008). However, one disadvantage is that it is difficult to establish an absolute hierarchical order among all the optimization objectives in some applications. Furthermore, in some cases, the less important objectives are not considered at all if there are not enough degrees of freedom in the subsequent optimization stages (optimizing according to the less important objectives) after the prior stages. To reduce the sensitivity of the final solution to the objective ranking, a variation of the lexicographic approach is proposed, which the constraints are formulated as Eq. (17).

\subsection{Lexicographic Optimization Approach to Berth Schedule Recovery}

Usually, the contracts between terminal operators and shipping companies specify the details of vessel operation time, thus different vessels have different sensitivity to operation delay. Furthermore, the importance of different shipping companies to terminal operators is also different. Therefore, in the berth schedule recovery, the objective hierarchical order is different for different kinds of vessels.

According to customer importance and delay sensitivity, vessels are segmented to three types, namely, key line vessels, trunk line vessels and feeder line vessels. (the segmentation criterion is shown in Table 1). Based on this segmentation, the berth schedule recovery is solved by three stages, namely, rescheduling key line vessels first, then, trunk line vessels, and finally feeder line vessels.

\section{The first stage: recovery model for key line vessels}

Key line vessels are most sensitive to delay, and there are strict constraints to vessel turnaround time in contracts between terminal operator and shipping companies. Therefore, key line vessels should be considered first in berth schedule recovery, and vessel delay $f_{2}$ is the most important objective. Meanwhile, $f_{3}$ is also impor- 
Table 1. Customer segmentation criterion

\begin{tabular}{|l|l|l|l|}
\hline \multicolumn{1}{|c|}{ Criterion } & \multicolumn{1}{c|}{ Key line vessels } & \multicolumn{1}{c|}{ Trunk line vessels } & \multicolumn{1}{c|}{ Feeder line vessels } \\
\hline Type of shipping lines & key lines & international trunk lines & short or feeder lines \\
\hline Sensitivity to delay & very sensitive & sensitive & not sensitive \\
\hline Importance to terminal operators & very important & very important & important \\
\hline Penalty cost to delay & very high & high & normal \\
\hline
\end{tabular}

tant objective as the changing of berthing location and time may result in increasing of system adjust time and decreasing of system reliability:

$$
\begin{aligned}
& \text { Lex } \min \left(f_{2}, f_{3}, f_{1}\right) \\
& \text { s. t. }(4)-(13) ;
\end{aligned}
$$

(16).

The second stage: recovery model for trunk line vessels

Vessels of international trunk lines are important customers for terminal operators and also have high sensitivity to delay. When modifying berth plan for this kind of vessel, vessel delay is the most important objective, then the operation cost and finally the deviation of berthing location and time:

$$
\begin{aligned}
& \text { Lex } \min \left(f_{2}, f_{1}, f_{3}\right) \\
& \text { s. t. }(4)-(13) ;
\end{aligned}
$$

(16).

\section{The third stage: recovery model for feeder line vessels}

Comparing to vessels of key and trunk lines, feeder line vessels are more flexible in operation and are less sensitive to vessel delay in terminals. Therefore, for berth schedule recovery of this kind of vessels, the objective order is operation cost, schedule deviation and vessel delay:

$$
\operatorname{Lex} \min \left(f_{1}, f_{3}, f_{2}\right)
$$

s. t. (4)-(13);

(16).

\section{Solution Algorithms}

The design of solution algorithms is based on vessel segmentation and objective sequential optimization. The process of berth schedule recovery is divided into three stages (as shown in Fig. 1), namely, rescheduling key line vessels first, then, trunk line vessels, and finally feeder line vessels. In each stage, the lexicographic optimization approach is used.

In the first stage, the algorithms are iterated three times. In the first iteration, the berth schedule is optimized according to objective $f_{2}$, and an optimal value $f_{2}^{*}$ is obtained. In the second iteration, the objective function is $f_{3}$, and $f_{2} \leq(1+\delta) f_{2}^{*}$ is added to constraints. At the end of the second iteration, the optimal value $f_{3}^{*}$ for $f_{3}$ is obtained. In the third iteration, the objective function is $f_{1}$, and $f_{2} \leq(1+\delta) f_{2}^{*}, f_{3} \leq(1+\delta) f_{3}^{*}$ is added to constraints.

The processes of the second and third stages are similar to the first stage. The objective sequential orders

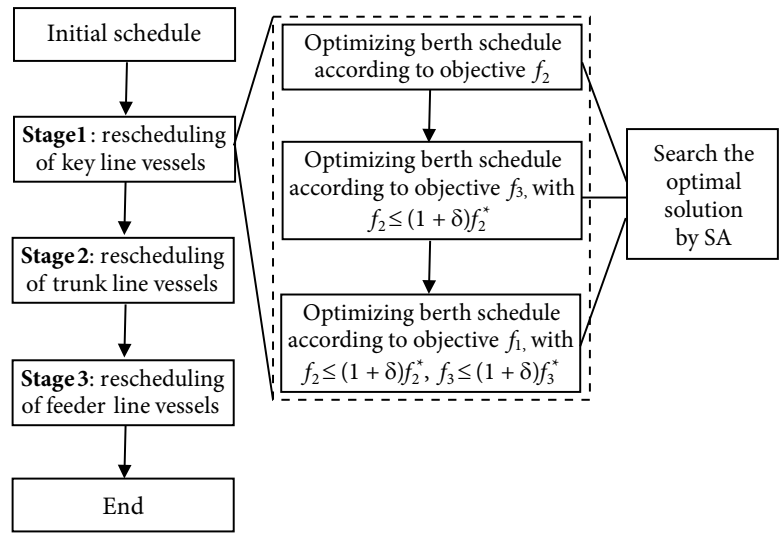

Fig. 1. Process of the proposed algorithm

are given by Eqs (19-20). In iterations of each stage, SA is used to search the optimal solution.

SA is based on the simulation of the annealing of solids and applied to solving large-scale combinatorial optimization problems. A standard SA procedure begins by generating an initial solution randomly. In each iterations of computing process, the new solution taken from the neighbour of the current solution is accepted as the new current solution if it has a lower or equal cost; if it has a higher cost it is accepted with a probability that decreases as the difference in the costs increases and as the temperature of the method decreases. The temperature is periodically reduced by a temperature scheme, it moves gradually from a relatively high value to near zero as the method progresses. The main operations of SA are as follows.

Encoding and decoding of solutions. To use SA algorithm solving the scheduling problem, an encoding method to represent the feasible solutions is used. The feasible solutions for the problem are coded into strings of integer numbers. Each string represents a berthing position scheme, and its length is equal to the number of vessels.

Generation mechanism of neighbour solution. To implement the SA algorithm, we need to generate a sequence of iterations, of which each is composed of changing the current solution in a designed way to create a neighbour solution. Here, two methods, namely swapping moves and varying moves are used to obtain neighbour solutions. 'Swapping' moves are to exchange the berthing position of two vessels. 'Varying' moves change berth location by moving one unite each time (10 m/move). In neighbour space searching, each 'swapping' move includes multiple 'varying' moves. 
Acceptance criterion for the neighbour solution. Once a neighbour solution is generated, the following criterion is adopted to judge whether to accept it or not:

$$
\text { Let } \Delta=f(s)-f\left(s_{0}\right) \text {, }
$$

where: $s_{0}$ denotes the current solution and $s$ denotes the neighbour solution generated from current solution; $f\left({ }^{\star}\right)$ denotes the objective function value.

$$
\text { If: }
$$

$$
r \leq e^{-\Delta / T_{i}},
$$

where: a random number $r$ in $(0,1)$ is generated from a uniform distribution; $T_{i}$ represents the current temperature.

Then the neighborhood will be accepted as the current solution, else, the current solution will remain unchanged.

Temperature updating scheme. The temperature is updated by the following formula:

$$
T_{i+1}=\frac{T_{i}}{1+\beta T_{i}}, i=1, \ldots, K-1,
$$

where: $\beta$ is the rate parameter in terms of the initial temperature $T_{i}$, stopping temperature $T_{K}$ and iteration number $K$ :

$$
\beta=\frac{T_{1}-T_{K}}{(K-1) T_{1} T_{K}} .
$$

Stopping criterion. After a pre-determined iteration is reached, algorithm stops. The minimum iterations for 'swapping' and 'varying' moves are 50, 20 respectively.

\section{Numerical Experiments}

Numerical examples are given to illustrate the validity of proposed Model A and algorithms. Data of a container terminal in Dalian Port are used. Vessel arrival data from July 4 to July 11 in 2010 are selected. The length of berth line is 1200 meters, and the number of quay cranes is 12 . The unit efficiency of quay cranes is 30 moves $/ \mathrm{h}$. $c_{1 i}, c_{2 i}$ and $c_{3}$ are set to $11 l_{i} / 23 \mathrm{USD} / \mathrm{m}, 210 l_{i} / 23 \mathrm{USD} / \mathrm{h}$ and 210 USD respectively.

There are 23 vessels which are considered in the plan horizon. The numbers of key line vessels, trunk line vessels and feeder line vessels are supposed to be 8,10 and 7 respectively. Supposing that operation of vessel 2 is delayed for 12 hours. MatLab is used to code the pro-

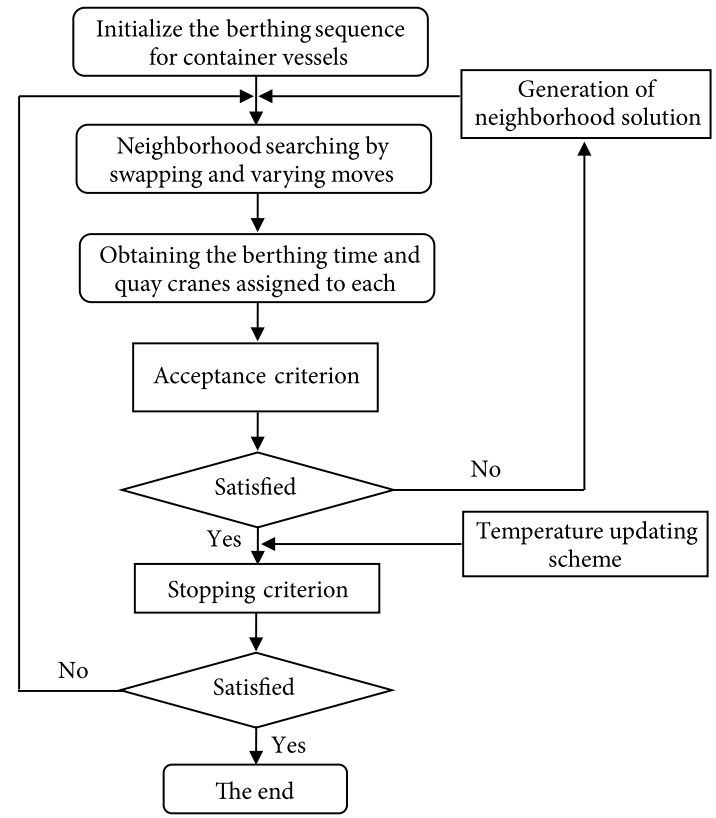

Fig. 2. The process of SA

gram and computer with Intel Core i5 $(2.50 \mathrm{GHz}) \mathrm{CPU}$ (Central Processing Unit) is used to run the program. The results for different $\delta$ are shown in Table 2. The average CPU time is 860 seconds.

Results indicate that vessel delay and additional cost for yard trailers are influenced by $\delta$. For key line and trunk line vessels, vessel delay increases and additional yard trailer cost decrease with the increase of $\delta$, and it is opposite for feeder line vessels. With the increase of $\delta$, the total vessel delay increase and the total additional cost for yard trailer decrease. Therefore, different Pareto optimal points can be generated by varying $\delta$ to tighten or relax the constraints. E.g., the benefit for key and trunk line vessel is more addressed by decreasing tolerance percentage $\delta$.

Furthermore, 8 scenarios are set supposing vessels $2,6,8,10,12,14,15,19$ are delayed 12 hours separately. The lexicographic optimization method proposed in this paper (we call it Model A) is compared with the method converting the problem into a single objective optimisation problem (we call it Model B). In Model B, the objective function is the sum of cost of vessel delay, additional costs resulting from non-optimal berth loca-

Table 2. Results for lexicographic optimization method

\begin{tabular}{|c|c|c|c|c|c|c|c|c|}
\hline \multirow{2}{*}{$\delta$} & \multicolumn{4}{|c|}{ Vessel delay [h] } & \multicolumn{4}{c|}{ Additional cost for yard trailers [USD] } \\
\cline { 2 - 9 } & Total & $\begin{array}{c}\text { Key line } \\
\text { vessels }\end{array}$ & $\begin{array}{c}\text { Trunk line } \\
\text { vessels }\end{array}$ & $\begin{array}{c}\text { Feeder line } \\
\text { vessels }\end{array}$ & Total & $\begin{array}{c}\text { Key line } \\
\text { vessels }\end{array}$ & $\begin{array}{c}\text { Trunk line } \\
\text { vessels }\end{array}$ & $\begin{array}{c}\text { Feeder line } \\
\text { vessels }\end{array}$ \\
\hline 0 & 287.6 & 6.7 & 86.7 & 196.5 & 3720.4 & 1822.0 & 1214.2 & 642.0 \\
\hline 0.02 & 301.1 & 12.4 & 103.6 & 175.4 & 3574.7 & 1614.1 & 1075.3 & 874.7 \\
\hline 0.04 & 306.4 & 21.2 & 119.7 & 167.3 & 3534.5 & 1587.2 & 1043.7 & 929.4 \\
\hline 0.06 & 310.0 & 22.7 & 131.0 & 157.4 & 3372.9 & 1344.7 & 984.3 & 1063.1 \\
\hline 0.08 & 316.2 & 32.8 & 136.9 & 148.0 & 3294.3 & 1282.0 & 924.2 & 1085.8 \\
\hline 0.10 & 319.4 & 34.9 & 147.5 & 137.3 & 3164.0 & 1174.8 & 875.0 & 1130.5 \\
\hline
\end{tabular}


tions of vessels, operation cost of quay cranes, and the penalty resulting from deviation between recovery and initial schedule:

$$
\begin{aligned}
& \min \sum_{i=1}^{N}\left(c_{1 i}\left|x_{i}-b_{i}\right|+c_{3} \sum_{t \in T} r_{i t}\right)+ \\
& \sum_{i=1}^{N} c_{2 i}\left(e_{i}-d_{i}\right)^{+}+\sum_{i=1}^{N} c_{3 i}\left(x_{i}-x_{i}^{0}\right)^{+}
\end{aligned}
$$$$
\text { s. t. (4)-(13). }
$$

Results are shown in Table 3. Results indicate that the proposed model (Model A) increases the total vessel delay and yard trailer operation cost comparing with Model B. The total vessel delay increase $2 \%$ and the average yard trailer operation cost increase $3.5 \%$, while the delay for key line vessels decreases greatly. Moreover, schedule deviation decreases greatly in proposed Model $A$ as the schedule deviation is treated as the second or third objective in key line vessels recovery.

Although the proposed model increases total vessel delay, it is more feasible to practical application considering that the delay costs of key line and trunk line vessels are high and have serious impact on terminal development. In addition, the proposed model decreases the schedule deviation, thus reduces the influence of disruption events on operation system.

In addition, experiments are used to find the influence of vessel configuration. Based on Scenario 1 in Ta- ble 3, seven scenarios are designed by increasing key line vessels, decreasing trunk and feeder line vessels. Results are given in Table 4 .

With the increase of key line vessels, the total vessel delay increases firstly, and then decreases. When the number of key line vessels is more than 15 , the total vessel delay of Model A is less than that of Model B. This is because that vessel delay is the most important objective when recovering schedule for key line vessels, total vessel delay decreases with the increase of key line vessel ratio. In addition, the operation cost for yard trailers increases with the increase of key line vessels, which indicates that the cost of berth schedule recovery increases with the increase of key line vessels.

\section{Conclusions}

In this paper, a multi-stage and multi-objective model is proposed to minimize the negative impacts of disruptions on berth schedule. Moreover, a method based on lexicographic optimization is designed to solve the model. Numerical experiments indicate the validity of the proposed Model A and algorithms. The model considers the characteristics of different customers and beneficial trade-off of all parties involved, thus can improve the scientific berth schedule recovery. Moreover, it is more flexible and feasible in the aspect of practical applications as the objective order can be adjusted by decision makers.

Table 3. Results for different scenarios

\begin{tabular}{|c|c|c|c|c|c|c|c|c|c|}
\hline \multicolumn{2}{|c|}{ Scenarios } & \multicolumn{4}{|c|}{ Model A } & \multicolumn{4}{c|}{ Model B } \\
\hline No & $\begin{array}{c}\text { Delayed } \\
\text { vessel }\end{array}$ & $\begin{array}{c}\text { Total vessel } \\
\text { delay [h] }\end{array}$ & $\begin{array}{c}\text { Delay for } \\
\text { key line } \\
\text { vessels [h] }\end{array}$ & $\begin{array}{c}\text { Cost increase } \\
\text { for yard } \\
\text { trailer [USD] }\end{array}$ & $\begin{array}{c}\text { Schedule } \\
\text { deviation } f_{3} \\
{[\mathrm{~m}]}\end{array}$ & $\begin{array}{c}\text { Total } \\
\text { vessel } \\
\text { delay [h] }\end{array}$ & $\begin{array}{c}\text { Delay for } \\
\text { key line } \\
\text { vessels [h] }\end{array}$ & $\begin{array}{c}\text { Cost increase } \\
\text { for yard trailer } \\
{[\text { USD] }}\end{array}$ & $\begin{array}{c}\text { Schedule } \\
\text { deviation } f_{3} \\
{[\mathrm{~m}]}\end{array}$ \\
\hline 1 & 2 & 256.0 & 5.3 & 3,457 & 638 & 279.2 & 61.0 & 2,894 & 713 \\
\hline 2 & 6 & 231.8 & 4.5 & 3,934 & 510 & 207.0 & 39.5 & 3,382 & 579 \\
\hline 3 & 8 & 225.7 & 6.2 & 2,878 & 427 & 212.7 & 50.3 & 2,475 & 543 \\
\hline 4 & 10 & 213.3 & 5.4 & 3,258 & 162 & 213.5 & 37.2 & 2,760 & 307 \\
\hline 5 & 12 & 204.1 & 5.2 & 3,128 & 96 & 209.7 & 36.8 & 2,735 & 283 \\
\hline 6 & 14 & 192.9 & 4.6 & 3,076 & 63 & 192.0 & 34.7 & 2,674 & 141 \\
\hline 7 & 15 & 204.3 & 4.2 & 3,055 & 81 & 195.9 & 29.0 & 2,631 & 165 \\
\hline 8 & 19 & 258.2 & 1.6 & 3,173 & 68 & 242.7 & 24.3 & 2,762 & 129 \\
\hline
\end{tabular}

Table 4. Results for different vessel configuration

\begin{tabular}{|c|c|c|c|c|c|c|c|c|c|}
\hline \multicolumn{2}{|c|}{ Scenarios } & \multicolumn{4}{|c|}{ Model A } & \multicolumn{4}{c|}{ Model B } \\
\hline No & $\begin{array}{c}\text { Number } \\
\text { of key } \\
\text { line } \\
\text { vessels }\end{array}$ & $\begin{array}{c}\text { Total vessel } \\
\text { delay [h] }\end{array}$ & $\begin{array}{c}\text { Delay for } \\
\text { key line } \\
\text { vessels [h] }\end{array}$ & $\begin{array}{c}\text { Cost increase } \\
\text { for yard } \\
\text { trailer [USD] }\end{array}$ & $\begin{array}{c}\text { Schedule } \\
\text { deviation } f_{3} \\
{[\mathrm{~m}]}\end{array}$ & $\begin{array}{c}\text { Total } \\
\text { vessel } \\
\text { delay [h] }\end{array}$ & $\begin{array}{c}\text { Delay for } \\
\text { key line } \\
\text { vessels [h] }\end{array}$ & $\begin{array}{c}\text { Cost increase } \\
\text { for yard trailer } \\
{[\text { USD] }}\end{array}$ & $\begin{array}{c}\text { Schedule } \\
\text { deviation } f_{3} \\
{[\mathrm{~m}]}\end{array}$ \\
\hline 1 & 2 & 260.2 & 0.0 & 3,210 & 406 & 263 & 61.7 & 2,919 & 713 \\
\hline 2 & 5 & 261.6 & 0.0 & 3,172 & 602 & 263 & 61.7 & 2,919 & 713 \\
\hline 3 & 8 & 270.3 & 5.7 & 3,201 & 659 & 263 & 61.7 & 2,919 & 713 \\
\hline 4 & 10 & 289.7 & 17.3 & 3,217 & 673 & 263 & 61.7 & 2,919 & 713 \\
\hline 5 & 15 & 251.8 & 42.0 & 3,741 & 739 & 263 & 61.7 & 2,919 & 713 \\
\hline 6 & 20 & 244.0 & 109.3 & 3,477 & 712 & 263 & 61.7 & 2,919 & 713 \\
\hline 7 & 23 & 230.7 & 207.4 & 3,709 & 718 & 263 & 61.7 & 2,919 & 713 \\
\hline
\end{tabular}


The objective of disruption management for berth schedule is to obtain modification scheme efficiently after disruptions happen. In fact, the recovery cost can be reduced by improving the schedule robust at the stage of berth planning. Moreover, the analysis and evaluation of disruption events are also helpful to forming of robust scheduling strategy. Therefore, the combination of robust scheduling and disruption management is a new and valid method of container terminal scheduling under uncertainty, which is an interesting topic for future study.

\section{References}

Abdelghany, K. F.; Abdelghany, A. F.; Ekollu, G. 2008. An integrated decision support tool for airlines schedule recovery during irregular operations, European Journal of Operational Research 185(2): 825-848.

http://dx.doi.org/10.1016/j.ejor.2006.12.045

Angeloudis, P.; Bell, M. G. H. 2010. An uncertainty-aware AGV assignment algorithm for automated container terminals, Transportation Research Part E: Logistics and Transportation Review 46(3): 354-366.

http://dx.doi.org/10.1016/j.tre.2009.09.001

Clausen, J.; Larsen, A.; Larsen, J.; Rezanova, N. J. 2010. Disruption management in the airline industry: concepts, models and methods, Computers \& Operations Research 37(5): 809-821. http://dx.doi.org/10.1016/j.cor.2009.03.027

Han, X.-L.; Lu, Z.-Q.; Xi, L.-F. 2010. A proactive approach for simultaneous berth and quay crane scheduling problem with stochastic arrival and handling time, European Journal of Operational Research 207(3): 1327-1340.

http://dx.doi.org/10.1016/j.ejor.2010.07.018

Imai, A.; Chen, H. C.; Nishimura, E.; Papadimitriou, S. 2008. The simultaneous berth and quay crane allocation problem, Transportation Research Part E: Logistics and Transportation Review 44(5): 900-920.

http://dx.doi.org/10.1016/j.tre.2007.03.003

Imai, A.; Nishimura, E.; Hattori, M.; Papadimitriou, S. 2007. Berth allocation at indented berths for mega-containerships, European Journal of Operational Research 179(2): 579-593. http://dx.doi.org/10.1016/j.ejor.2006.03.034

Imai, A.; Nishimura, E.; Papadimitriou, S. 2003. Berth allocation with service priority, Transportation Research Part B: Methodological 37(5): 437-457. http://dx.doi.org/10.1016/S0191-2615(02)00023-1

Imai, A.; Sun, X.; Nishimura, E.; Papadimitriou, S. 2005. Berth allocation in a container port: using a continuous location space approach, Transportation Research Part B: Methodological 39(3): 199-221.

http://dx.doi.org/10.1016/j.trb.2004.04.004

Kerrigan, E. C.; Maciejowski, J. M. 2002. Designing model predictive controllers with prioritised constraints and objectives, in Proceedings: 2002 IEEE International Symposium on Computer Aided Control System Design, 18-20 September 2002, Glasgow, Scotland, UK, 33-38. http://dx.doi.org/10.1109/CACSD.2002.1036925

Kim, K. H.; Moon, K. C. 2003. Berth scheduling by simulated annealing, Transportation Research Part B: Methodological 37(6): 541-560.

http://dx.doi.org/10.1016/S0191-2615(02)00027-9

Kuster, J.; Jannach, D.; Friedrich, G. 2008. Extending the RCPSP for modeling and solving disruption management problems, Applied Intelligence 31(3): 234-253.

http://dx.doi.org/10.1007/s10489-008-0119-x
Li, D. 1996. Convexification of a noninferior frontier, Journal of Optimization Theory and Applications 88(1): 177-196. http://dx.doi.org/10.1007/BF02192028

Liang, C.; Huang, Y.; Yang, Y. 2009. A quay crane dynamic scheduling problem by hybrid evolutionary algorithm for berth allocation planning, Computers \& Industrial Engineering 56(3): 1021-1028.

http://dx.doi.org/10.1016/j.cie.2008.09.024

Liu, T.-K.; Jeng, C.-R.; Chang, Y.-H. 2008. Disruption management of an inequality-based multi-fleet airline schedule by a multi-objective genetic algorithm, Transportation Planning and Technology 31(6): 613-639.

http://dx.doi.org/10.1080/03081060802492652

Marler, R. T.; Arora, J. S. 2004. Survey of multi-objective optimization methods for engineering, Structural and Multidisciplinary Optimization 26(6): 369-395.

http://dx.doi.org/10.1007/s00158-003-0368-6

Meisel, F.; Bierwirth, C. 2009. Heuristics for the integration of crane productivity in the berth allocation problem, Transportation Research Part E: Logistics and Transportation Review 45(1): 196-209.

http://dx.doi.org/10.1016/j.tre.2008.03.001

Miettinen, K. 1998. Nonlinear Multiobjective Optimization. Springer. 298 p.

Nishimura, E.; Imai, A.; Papadimitriou, S. 2001. Berth allocation planning in the public berth system by genetic algorithms, European Journal of Operational Research 131(2): 282-292. http://dx.doi.org/10.1016/S0377-2217(00)00128-4

Ocampo-Martinez, C.; Ingimundarson, A.; Puig, V.; Quevedo, J. 2008. Objective prioritization using lexicographic minimizers for MPC of sewer networks, IEEE Transactions on Control Systems Technology 16(1): 113-121. http://dx.doi.org/10.1109/TCST.2007.899741

Oke, A.; Gopalakrishnan, M. 2009. Managing disruptions in supply chains: a case study of a retail supply chain, International Journal of Production Economics 118(1): 168-174. http://dx.doi.org/10.1016/j.ijpe.2008.08.045

Park, Y.-M.; Kim, K. H. 2003. A scheduling method for berth and quay cranes, OR Spectrum: Quantitative Approaches in Management 25(1): 1-23. http://dx.doi.org/10.1007/s00291-002-0109-Z

Prats, X.; Puig, V.; Quevedo, J.; Nejjari, F. 2010. Lexicographic optimisation for optimal departure aircraft trajectories, Aerospace Science and Technology 14(1): 26-37. http://dx.doi.org/10.1016/j.ast.2009.11.003

Petrovic, D.; Duenas, A. 2006. A fuzzy logic based production scheduling/rescheduling in the presence of uncertain disruptions, Fuzzy Sets and Systems 157(16): 2273-2285. http://dx.doi.org/10.1016/j.fss.2006.04.009

Qi, X.; Bard, J. F.; Yu, G. 2006. Disruption management for machine scheduling: the case of SPT schedules, International Journal of Production Economics 103(1): 166-184. http://dx.doi.org/10.1016/j.ijpe.2005.05.021

Walker, C. G.; Snowdon, J. N.; Ryan, D. M. 2005. Simultaneous disruption recovery of a train timetable and crew roster in real time, Computers \& Operations Research 32(8): 20772094. http://dx.doi.org/10.1016/j.cor.2004.02.001

Wang, F.; Lim, A. 2007. A stochastic beam search for the berth allocation problem, Decision Support Systems 42(4): 21862196. http://dx.doi.org/10.1016/j.dss.2006.06.008

Xiao, T.; Qi, X.; Yu, G. 2007. Coordination of supply chain after demand disruptions when retailers compete, International Journal of Production Economics 109(1-2): 162-179. http://dx.doi.org/10.1016/j.ijpe.2006.11.013

Yu, G.; Qi, X. 2004. Disruption Management: Framework, Models and Applications. World Scientific Pub Co Inc. 312 p. 